\title{
Die Kooperationsvereinbarungen der Sekretariate multilateraler Umweltschutzübereinkommen
}

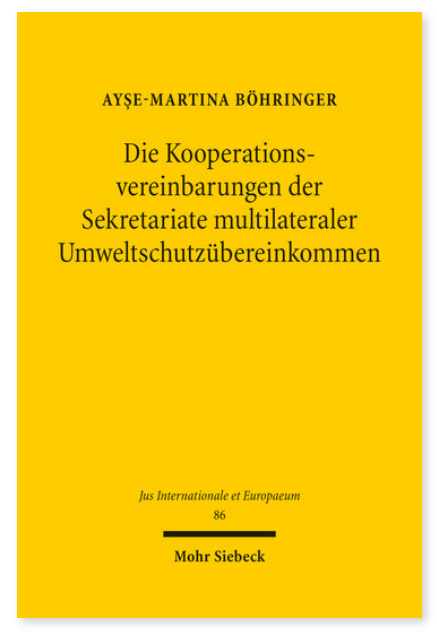

2014. XXIV, 349 Seiten. JusIntEu 86

ISBN 978-3-16-152875-0

DOI 10.1628/978-3-16-152875-0

eBook PDF $94,00 €$

ISBN 978-3-16-152861-3

fadengeheftete Broschur 94,00€
Ayşe-Martina Böhringer thematisiert die Kooperationsvereinbarungen von Sekretariaten multilateraler Umweltschutzübereinkommen aus völkerrechtlicher Perspektive und ordnet diese in den »Global Environmental Governance«-Prozess ein.

Das Umweltvölkerrecht ist aufgrund der zahlreichen, nebeneinander existierenden multilateralen Übereinkommen durch eine dezentrale und fragmentierte Struktur geprägt. Die Kooperationsvereinbarungen der Sekretariate multilateraler Umweltschutzübereinkommen haben sich vor dem Hintergrund eines Bedürfnisses nach mehr Kohärenz und Rechtssicherheit in ganz spezifischen Bereichen des Umweltvölkerrechts und zur Überwindung von Fragmentierung herausgebildet. Die Kernfrage - nämlich die rechtliche Beschreibung und Einordnung dieser Kooperationsvereinbarungen führt zu folgenden wesentlichen Untersuchungsschritten: Erstens zu der Frage der völkerrechtlichen Stellung der Sekretariate multilateraler Umweltschutzübereinkommen; zweitens zu einer möglichst repräsentativen Bestandsaufnahme der mit diesen Sekretariaten getroffenen Kooperationsvereinbarungen; drittens zu der Frage des normativen Potentials dieser Kooperationsvereinbarungen. Schließlich erfolgt eine funktionale Einordnung dieser Vereinbarungen. Dabei werden auch die Grenzen dieses eigendynamischen institutionellen Rechts(norm)setzungsprozesses und die tatsächliche Wirkmacht der Staaten als »Herren der Verträge« aufgezeigt, auch wenn - oder gerade weil - sich die Vereinbarungen weit überwiegend den traditionellen Rechtsnormkategorien nicht eindeutig zuordnen lassen.

Ayşe-Martina Böhringer Geboren 1982; Studium der Rechtswissenschaft an der Universität Gießen; 2007-11 Wissenschaftliche Mitarbeiterin am Lehrstuhl für Öffentliches Recht, Völkerrecht und Europarecht, Universität Gießen; 2013 Promotion; seit November 2011 Rechtsreferendarin am Landgericht Gießen und Wissenschaftliche Hilfskraft an der Universität Gießen.

Jetzt bestellen:

https://mohrsiebeck.com/buch/die-kooperationsvereinbarungen-der-sekretariate-multilateraler-

umweltschutzuebereinkommen-9783161528750?no_cache=1

order@mohrsiebeck.com

Telefon: +49 (0)7071-923-17

Telefax: +49 (0)7071-51104 